\title{
Evaluation of Spatial Working Memory Function in Children and Adults with Fetal Alcohol Spectrum Disorders: A Functional Magnetic Resonance Imaging Study
}

\author{
KRISZTINA L. MALISZA, AVA-ANN ALLMAN, DEBORAH SHILOFF, LORNA JAKOBSON, \\ SALLY LONGSTAFFE, AND ALBERT E. CHUDLEY

\begin{abstract}
National Research Council, Institute for Biodiagnostics [K.L.M., A.A.A., D.S.], Winnipeg, Manitoba, Canada, R3B 1Y6; Department of Physiology [K.L.M.], University of Manitoba, Bannatyne Campus, Winnipeg, Manitoba, Canada, R3E 3J7; Department of Psychology [L.J.], University of Manitoba, Winnipeg, Manitoba, Canada, R3T 2N2; Department of Pediatrics and Child Health [A.E.C.] and Child Development Clinic [S.L.], Children's Hospital, Health Sciences Centre, Winnipeg, University of Manitoba, Manitoba, Canada, R3E $3 P 5$
\end{abstract}

\begin{abstract}
Magnetic resonance imaging (MRI) and functional MRI studies involving n-back spatial working memory (WM) tasks were conducted in adults and children with Fetal Alcohol Spectrum Disorders (FASD), and in age- and sex-matched controls. FMRI experiments demonstrated consistent activations in regions of the brain associated with working memory. Children with FASD displayed greater inferior-middle frontal lobe activity, while greater superior frontal and parietal lobe activity was observed in controls. Control children also showed an overall increase in frontal lobe activity with increasing task difficulty, while children with FASD showed decreased activity. FASD adults demonstrated less functional brain activity overall, but greater inferiormiddle frontal lobe activity during the simpler tasks, relative to controls. Control adults demonstrated greater inferior frontal activity with increasing task difficulty, while this pattern was not consistently observed in FASD adults. All four groups showed increasing activity with increases in task difficulty in the parietal and frontal regions at more superior slice levels. The results
\end{abstract}

\section{ABSTRACT}

suggest impairment in spatial working memory in those with FASD that does not improve with age, and that fMRI may be useful in evaluation of brain function in these individuals. (Pediatr Res 58: 1150-1157, 2005)

$\quad$ Abbreviations
ARND, alcohol related neurodevelopmental disorder
CPT, Continuous Performance Task
DLPFC, dorsolateral prefrontal cortex
FAS, Fetal Alcohol Syndrome
FASD, Fetal Alcohol Spectrum Disorder
fMRI, functional magnetic resonance imaging
MRI, Magnetic Resonance Imaging
PET, positron emission tomography
SOP, Self Ordered Pointing
WCST, WI Card Sorting Task
WM, working memory

behavioral and cognitive deficits exhibiting minimal or no physical stigmata. The diagnosis of FAS and its spectrum is a challenge, especially in adults and children with ARND, as many of the symptoms are nonspecific and no neurodevelopmental profile has been established. Accurate diagnosis is important since many secondary disabilities could be prevented with appropriate intervention.

The effects of alcohol as a teratogen are well-documented, with prenatal alcohol exposure being associated with diverse and devastating neurodevelopmental deficits (1-4), which can
Received November 1, 2004; accepted June 14, 2005.

Correspondence: Krisztina L. Malisza, Ph.D., Research Officer, Institute for Biodiagnostics, 435 Ellice Avenue, Winnipeg, Manitoba, R3B 1Y6, Canada; e-mail: Kris.Malisza@nrc-cnrc.gc.ca Financial support was provided, in part, by the Manitoba Medical Services Foundation.

DOI: 10.1203/01.pdr.0000185479.92484.a1 
vary depending on when during pregnancy the alcohol was consumed (1). Children with prenatal alcohol exposure generally have lower intelligence (5), impairments in language, visual-spatial ability, fine-motor skills, nonverbal learning and academic performance, as well as psychiatric and behavioral problems (6). Although implicit memory may be spared, problems with explicit memory, affecting recall, may occur (7). Impairments in executive functions are also frequently seen in individuals with FAS (8), although Kodituwakku et al. (9) suggest that working memory (WM) may be affected to a greater extent than rule learning and response inhibition.

We used functional magnetic resonance imaging (fMRI) to examine patterns of brain activation during a spatial WM task in adults and children with FASD and age- and sex-matched controls. We also used MRI to examine whether quantitative anatomical differences could be observed between these subjects and nonFASD controls.

\section{METHODS}

The protocol was approved by the Winnipeg Research Ethics Board and University of Manitoba Research Ethics Board. Subjects were recruited through the Clinic for Alcohol and Drug Exposed Children, physicians' offices and collaboration with Manitoba Child and Family Services. Informed consent was obtained from all subjects over $18 \mathrm{y}$ of age and from parents/legal guardians of minors; written or verbal assent was obtained from all subjects under $18 \mathrm{y}$ of age.

Preparation. Each FASD participant's diagnosis was verified by qualified professionals using a standardized multidisciplinary approach (10). All participants were introduced to the WM task and the imaging environment before actually performing the experiment.

fMRI tasks and analysis. Functional imaging studies were conducted using a 1.5 T GE Signa LX MRI system. Both children $(n=14$, aged $7-12$ yr) and adults $(n=10$, aged $18-33$ yr) with FASD, and sex- and age-matched $( \pm 1$ yr) control subjects ( 15 children and 10 adults) participated in the study. Children with FASD were diagnosed with ARND $(n=5)$, partial FAS $(n=$ $6)$, or FAS $(n=3)$; adults were diagnosed with ARND $(n=6)$, partial FAS $(n=1)$, or FAS $(n=3)$.

In a series of $n$-back tasks, participants indicated, with a button press, the spatial location of a colored circle either during its presentation ( $n=0$, Simple task), at the end of a brief delay during which blank circles were presented $(n=1$, Blank task), or after presentation of one or two additional stimuli ( $n=1$, One-back task; $n=2$, Two-back task). Stimuli were viewed through MR compatible goggles. A total of 56 images were acquired for each experiment, in which 3 activation states were alternated with 4 rest periods. FMRI data were acquired using a gradient echo-echo planar imaging sequence with $64 \times 64$ matrix, $24 \mathrm{~cm}$ field of view, 50 $\mathrm{ms}$ echo time, $2 \mathrm{~s}$ repetition time, and 21 contiguous $5 \mathrm{~mm}$ thick slices oriented parallel to the anteroposterior commissure (AC-PC) line.

Images were converted with programs written in-house using MATLAB (Mathworks Inc., Natick, MA) set to Analyze format. FMRI data were analyzed using Statistical Parametric Mapping (11) by co-registering the images and normalizing them to a standard stereotaxic space using either a pediatric brain template (12) (child participants), or the Montreal Neurologic Institute brain template (adult participants) (13). The first two images of each series were discarded and data spatially smoothed with an $8 \mathrm{~mm}$ full width half maximum isotropic Gaussian kernel. The reference intensity time course was modeled with a simple block design with transitions between rest and task periods convolved with the theoretical hemodynamic response. Significance level for correlations between pixel intensity time courses and the model time course was set at $p<0.001$ for individual fMRI data and $p<0.01$ for individual subtraction data. FMRI maps for the 4 groups were generated using one sample $t$ tests $(p<0.01)$. Activation was assessed through volume and intensity of activated pixels in each anatomically-defined brain area. Functional activations were overlaid on one control adult and child T1-weighted anatomical images for comparison of active regions.

Anatomical imaging. Standard imaging sequences were used for anatomical imaging with a $24 \mathrm{~cm}$ field of view, $256 \times 192$ matrix, and 21 contiguous $5 \mathrm{~mm}$ thick slices, corresponding to those chosen for the fMRI experiments. Magnetization transfer images were acquired using a spin echo imaging sequence with echo time of $10 \mathrm{~ms}$ and repetition time of $500 \mathrm{~ms}$. Magnetization saturation was accomplished using Gaussian pulses with a $1500 \mathrm{~Hz}$ offset. The magnetization transfer ratio was calculated using a MATLAB program written in-house, by subtracting the presaturated from saturated image and dividing by the reference scan. Proton density and $T_{2}$ images were acquired using a fast spin echo sequence with a dual echo, effective echo time of $85 \mathrm{~ms}$, repetition time of $4 \mathrm{~s}$, and an echo train length of 8 , resulting in an acquisition time of just over three minutes. A standard GE spin echo inversion recovery sequence was used to obtain images at two different inversion times $(700 \mathrm{~ms}$ and $1000 \mathrm{~ms}$ ), to calculate $\mathrm{T}_{1}$ maps.

Psychological testing. In addition to completing the $n$-back tasks, all participants completed three standard psychological tests designed to assess working and strategic memory (Self Ordered Pointing Task or SOPT), vigilance (Continuous Performance Task or CPT), and aspects of executive function (Wisconsin Card Sorting Task or WCST). Control adults had significantly more formal schooling than FASD adults ( $4.8 \mathrm{y}$, on average). While the use of standard scores allowed for correction for age and education in the WCST, this group difference poses an interpretational concern for other measures.

\section{RESULTS}

$N$-back tasks. FASD subjects performed very poorly on the Two-back task, suggesting that it was either too difficult or confusing for them. Since this limited our ability to interpret activation patterns in this condition, it was dropped from the data analysis. In addition, to be included in the analyses of any of the behavioral tests, all participants had to achieve a minimum of 50\% correct responses on the Simple task, and on at least one of the remaining n-back tasks (Blank or One-back). Using this cut-off, complete data were available for 42 participants: 14 control children (8M:6F), 9 FASD children (3M:6F), 9 control adults (4M:5F), and 10 FASD adults (3M:7F).

Separate 2 (Group) $\times 2($ Age $) \times 3$ (Task) ANOVAs, with repeated measures on the last factor, were conducted on: (a) percent correct responses, (b) mean latency of correct responses, (c) percent incorrect responses, and (d) percent nonresponses. There were no main effects or interactions involving Age in any of the analyses, suggesting that the pattern of responding was similar for children and adults in each group.

Overall, individuals with FASD made fewer correct responses, had longer mean latencies during correct responses, and showed higher rates of both incorrect- and nonresponding than controls $[F(1,38)=18.81, p<0.001, F(1,38)=6.14, p<0.05, F(1,38)$ $=4.64, p<0.05$, and $F(1,38)=16.41, p<0.001$, respectively]. There were also significant Group $\times$ Task interactions in three of these analyses (except for analysis of percent incorrect responses). Follow-up (LSD) tests of simple main effects of Task revealed different patterns of responding in FASD and control participants. Controls were very accurate and performed in a consistent manner in all phases of testing, although they did take significantly longer to make correct responses during the One-back task than during the other tasks, $F(2,44)=80.5, p<0.001$. FASD participants were less consistent, being more accurate in the Blank task than in either the Simple or (especially) the One-back condition $[F(2,36)$ $=13.5, p<0.001]$ (see Fig. 1A). Their poor performance in the One-back task did not reflect a speed-accuracy trade-off, as mean correct response times were actually longer during this task than during the Blank task $[F(2,36)=24.1, p<0.001]($ Fig $1 B)$. They also exhibited high rates of nonresponding during the One-back task $[F(2,36)=6.7, p<0.005]$ (Fig. 1C). This task also produced the highest rates of incorrect responses for all groups, $F(2,76)=$ $6.59, p<0.005$ (Fig. 1 D).

Wisconsin Card Sorting Test (WCST). A 2 (Group) $\times 2$ (Age) multivariate analysis of variance (MANOVA) was conducted on standard scores obtained on the WCST for the following mea- 


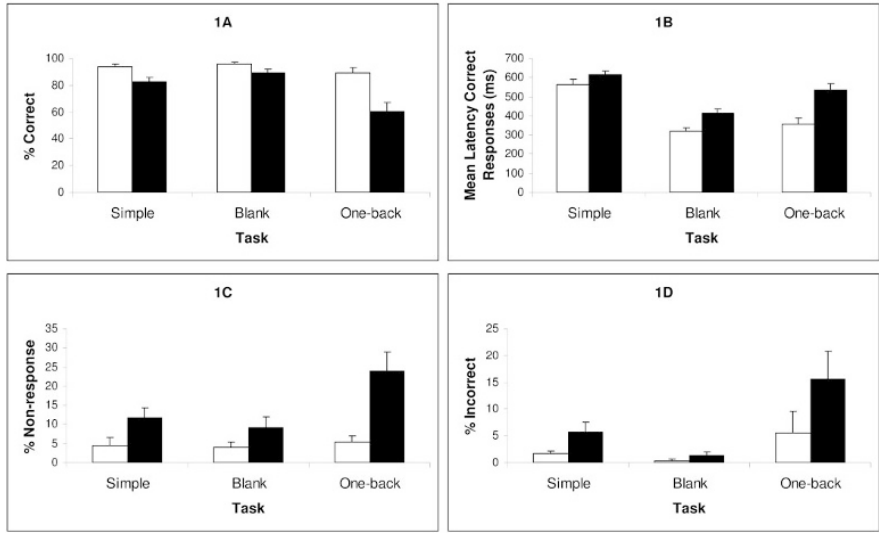

Figure 1. Mean scores in each of the $n$-back tasks for Control (open bars; 14 children; 9 adults) and FASD (filled bars; 9 children; 10 adults) participants (SE indicated). (A) percent correct response, $(B)$ mean latency of correct responses $(\mathrm{ms}),(C)$ percent nonresponse, and $(D)$ percent incorrect response.

a)

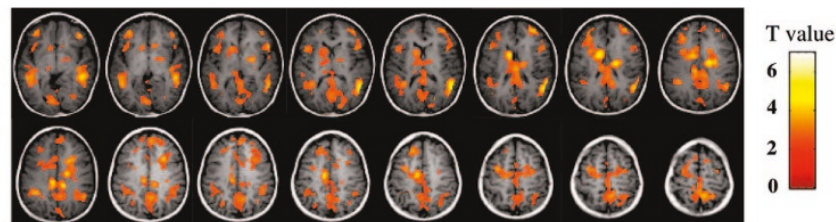

b)

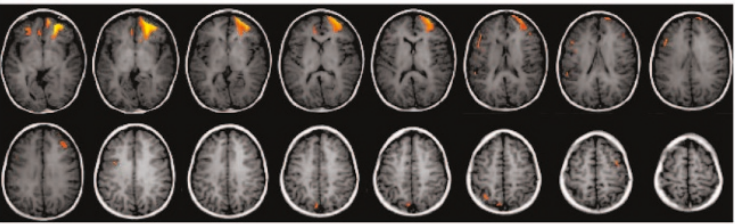

c)

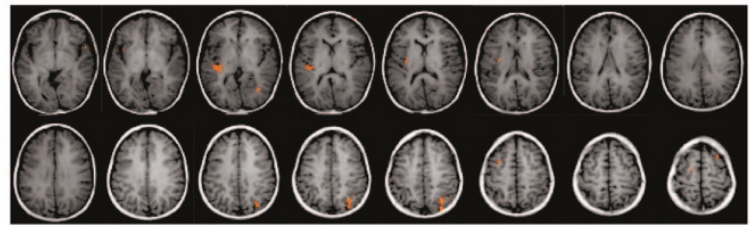

Figure 2. Individual activations for the Blank minus Simple task in three, 11-y-old female subjects: $a$ ) FAS, $b$ ) partial FAS and $c$ ) control. Activations are shown at a level of $p \leq 0.01$. The data are presented in radiologic orientation; left side of the image is right side of the brain.

a)

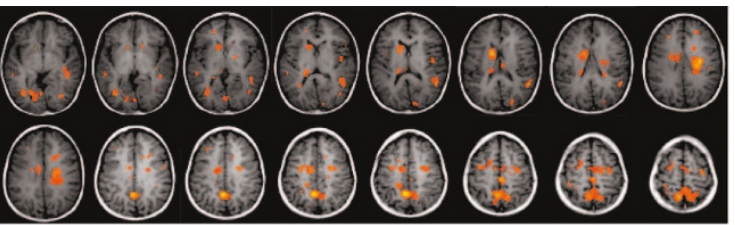

b)

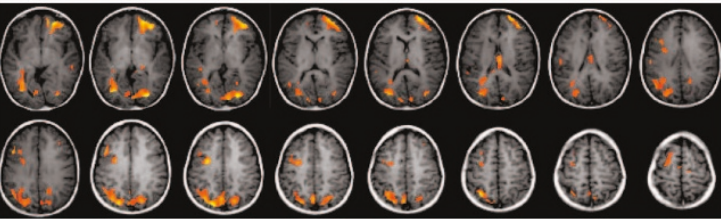

c)

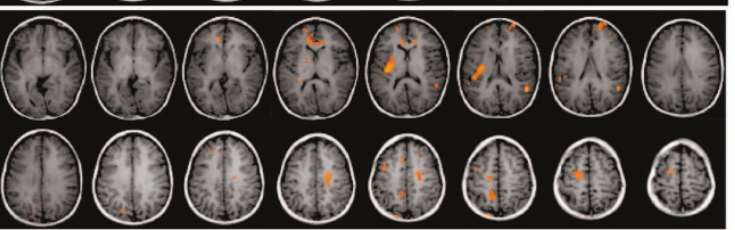

Figure 3. Individual activations for the (One-Back) minus Simple task in three, 11-y-old female subjects: $(A)$ FAS, $(B)$ partial FAS and $(C)$ control. Activations are shown at a level of $p \leq 0.01$. The data are presented in radiologic orientation; left side of the image is right side of the brain. a)

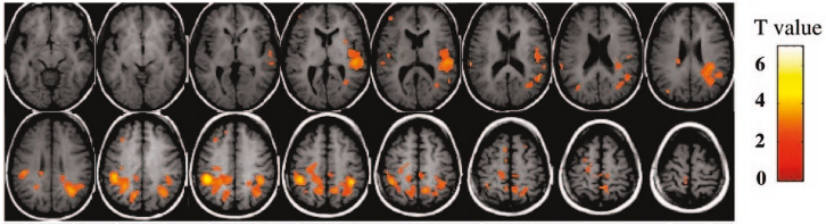

b)

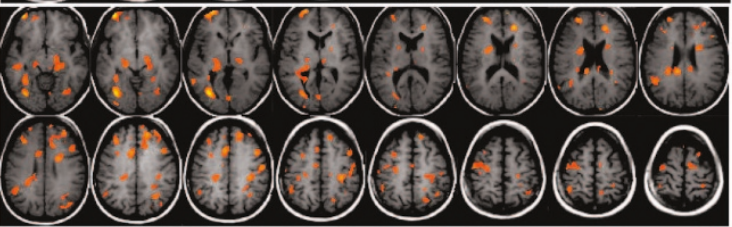

c)



Figure 4. Individual activations for the Blank minus Simple task in $a$ ) 26-y-old female with ARND, b) 25-y-old female with FAS and c) 26-y-old female control. Activations are shown at a level of $p \leq 0.01$. The data are presented in radiologic orientation; left side of the image is right side of the brain.

a)

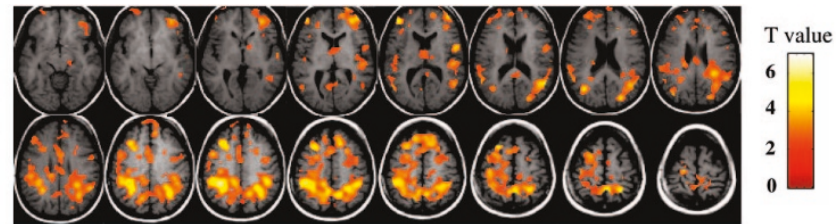

b)

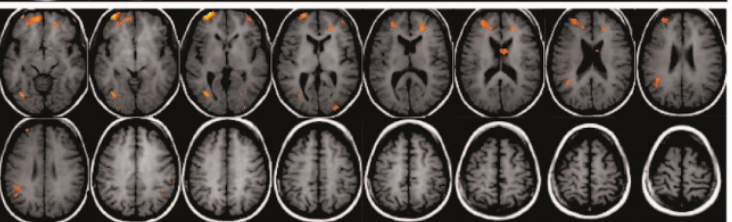

c)

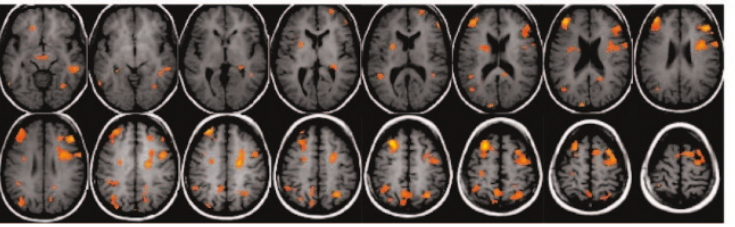

Figure 5. Individual activations for the One-Back minus Simple task in $a$ ) 26-y-old female with ARND, b) 25-y-old female with FAS and $c$ ) 26-y-old female control. Activations are shown at a level of $p \leq 0.01$. The data are presented in radiologic orientation; left side of the image is right side of the brain.

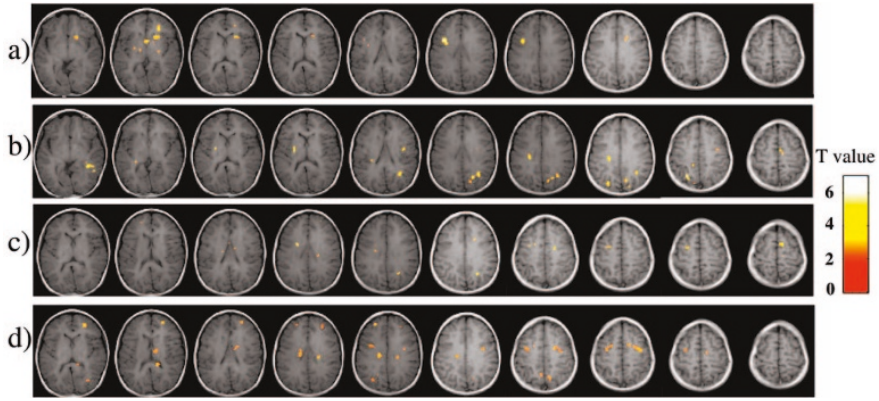

Figure 6. One sample $t$ test demonstrating FMRI Group activity at a level of $p<0.01$ for the Blank task in $(A)$ FASD children $(n=9),(B)$ control children $(n=8)$, and the One-back task in $(C)$ FASD children $(n=7)$, and d) control children $(n=8)$, following subtraction of the Simple task. 


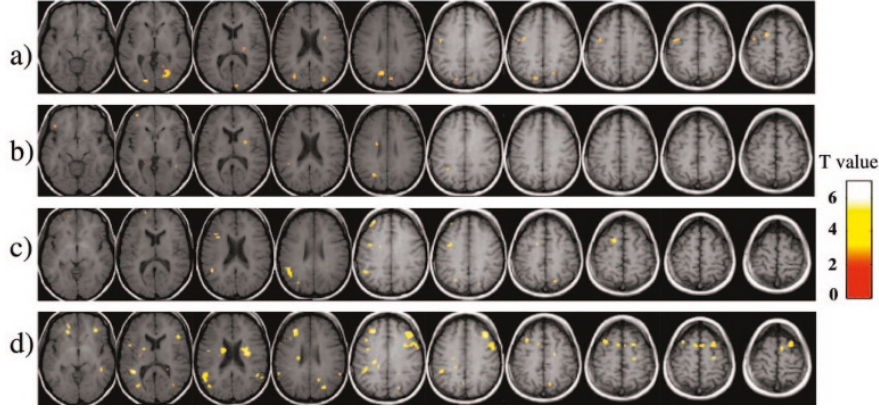

Figure 7. One sample $t$ test demonstrating FMRI Group activity at a level of $p<0.01$ for the Blank task in (A) FASD adults $(n=10),(B)$ control adults $(n=9)$, and the One-back task in $(C)$ FASD adults $(n=6)$, and $(D)$ control adults $(n=6)$, following subtraction of the Simple task.

sures: total errors, perseverative responses, perseverative errors, nonperseverative errors, and percent conceptual level responses. Number of categories achieved was included as a sixth dependent variable in this analysis. There were no significant main effects or interactions in this omnibus test (Wilks' Lambda criterion).

A nonparametric approach was also used to examine performance on the WCST. Each standard score was coded along a four-point scale: 1) average to above-average $(>92), 2$ ) below average $(85-91), 3)$ borderline $(70-84)$, and 4) deficient $(<70)$. The number of categories a given participant achieved was also coded on a four-point scale using percentile norms for his/her age: 1) $>16^{\text {th }}$ percentile, 2) $11^{\text {th }}-16^{\text {th }}$ percentile, 3) $6^{\text {th }}-10^{\text {th }}$ percentile, or 4$)<6^{\text {th }}$ percentile. Ranked scores for each variable were entered into two sets of Mann-Whitney tests: one comparing FASD and control children, and a second comparing FASD and control adults. Although no differences in performance were observed between the two groups of children, trends $(p<0.10)$ toward group differences favoring controls were evident on all measures in adult participants.

Self-ordered Pointing Task (SOPT). Total errors on the SOPT were entered into a 2 (Group) $\times 2$ (Age) ANOVA. A significant main effect of Age, $F(1,38)=5.03, p<0.05$, revealed that children found the task quite challenging, committing on average 17.6 errors $(S D=8.7)$ compared with 12.4 errors $(S D=8.3)$ for adults. Significant Group effects were observed, $F(1,38)=4.88, p<0.05$; individuals with FASD committed many more errors $(M=17.8, S D=8.6)$ than controls $(M=13.1, S D=8.6)$ overall.

Continuous Performance Test (CPT). A 2 (Group) $\times 2$ (Age) MANOVA conducted on the four performance measures from the CPT produced significant main effects of both Age, $F(4,34)=$ 4.28, $p<0.01$, and Group, $F(4,34)=4.03, p<0.01$ (Wilks' Lambda criterion). Follow-up univariate tests showed children performed worse than adults on all four indices: 1) percent correct responses, $F(1,37)=8.33, p<0.01,2)$ mean latency correct responses, $F(1,37)=4.75, p<0.05,3)$ probability of a hit, $F(1,37)=6.82, p<0.05$, and 4) probability of a false alarm, $F(1,37)=8.40, p<0.01$. In addition, individuals affected by FASD performed similarly to controls on all measures except one: the mean latencies of their correct responses were significantly longer than those of controls, $F(1,37)=8.51, p<0.01$. These results are of interest as they suggest group differences on other measures were unlikely due to group differences in ability to remain on-task.

FMRI. Consistent activations were observed at $p<0.001$ in brain regions associated with WM and attention (dorsolateral

Table 1. Selected regions of activity for comparison of FASD and control child subjects presented in Figures 2 and 3 during 1-back tasks following subtraction of the $n=0$ task $(p \leq 0.01)$

\begin{tabular}{|c|c|c|c|c|c|c|c|c|}
\hline Task/subject & Region of interest & Hemisphere & Brodmann's area & \multicolumn{3}{|c|}{ Coordinates } & Z-score & Cluster size \\
\hline Blank-Simple & & & & $\mathrm{x}$ & $\mathrm{y}$ & $\mathrm{z}$ & & \\
\hline \multirow{5}{*}{ FAS children } & & $\mathrm{R}$ & 10 & 24 & 58 & -8 & 5.03 & $2009 *$ \\
\hline & & $\mathrm{R}$ & 11 & 28 & 48 & -16 & 4.89 & $2009 *$ \\
\hline & Middle frontal gyrus & $\mathrm{L}$ & 10 & -34 & 52 & 0 & 3.55 & 238 \\
\hline & Inferior frontal gyrus & $\mathrm{L}$ & 45 & -48 & 26 & 18 & 4.00 & 782 \\
\hline & & $\mathrm{L}$ & 45 & -58 & 24 & 18 & 3.40 & $50 * *$ \\
\hline \multirow[t]{3}{*}{ Control child } & Inferior frontal gyrus & $\mathrm{R}$ & & 62 & 14 & -16 & 3.71 & 59 \\
\hline & Postcentral gyrus insula & $\mathrm{L}$ & 40 & -50 & -26 & 2 & 3.32 & 174 \\
\hline & & $\mathrm{L}$ & 13 & -40 & -12 & 10 & 2.52 & 39 \\
\hline \multicolumn{9}{|l|}{ 1-Back-Simple } \\
\hline \multirow{5}{*}{ FAS children } & & $\mathrm{L}$ & & -36 & 32 & 22 & 6.48 & 1019 \\
\hline & Inferior frontal gyrus & $\mathrm{L}$ & & -40 & 8 & 28 & 4.15 & 631 \\
\hline & Superior parietal lobule & $\mathrm{R}$ & 7 & 24 & -68 & 44 & 4.91 & $1253 \S$ \\
\hline & Precuneus & $\mathrm{R}$ & 19 & 28 & -78 & 34 & 4.82 & $1253 \S$ \\
\hline & Postcentral gyrus & $\mathrm{L}$ & 2 & -66 & -20 & 24 & 3.86 & 51 \\
\hline \multirow[t]{3}{*}{ Control child } & Superior frontal gyrus & $\mathrm{R}$ & 10 & 20 & 68 & 20 & 3.20 & 129 \\
\hline & & $\mathrm{L}$ & 6 & -22 & -6 & 64 & 3.56 & 245 \\
\hline & Insula & $\mathrm{L}$ & 13 & -40 & -14 & 12 & 4.29 & 578 \\
\hline
\end{tabular}

$*, * *, \S$ Local maxima within the same cluster. 
Table 2. Selected regions of activity for comparison of FASD and control adult subjects presented in Figures 4 and 5 during 1-back tasks following subtraction of the $n=0$ task $(p \leq 0.01)$

\begin{tabular}{|c|c|c|c|c|c|c|c|c|}
\hline \multirow[b]{2}{*}{ Task/subject } & \multirow[b]{2}{*}{ Region of interest } & \multirow[b]{2}{*}{ Hemisphere } & \multirow[b]{2}{*}{ Brodmann's area } & \multicolumn{3}{|c|}{ Coordinates } & \multirow[b]{2}{*}{ Z-score } & \multirow[b]{2}{*}{ Cluster size } \\
\hline & & & & $\mathrm{x}$ & $\mathrm{y}$ & $\mathrm{Z}$ & & \\
\hline \multicolumn{9}{|l|}{ Blank-Simple } \\
\hline \multirow[t]{11}{*}{ FAS adults } & Superior frontal gyrus & $\mathrm{L}$ & 10 & -24 & 54 & 22 & 3.94 & 603 \\
\hline & & $\mathrm{R}$ & 9 & 34 & 48 & 32 & 3.68 & $1115^{*}$ \\
\hline & Postcentral gyrus & $\mathrm{R}$ & 3 & 12 & -34 & 64 & 3.15 & 185 \\
\hline & Cingulate & & & -6 & 16 & 40 & 4.01 & 318 \\
\hline & Inferior parietal lobule & $\mathrm{R}$ & 40 & 44 & -44 & 44 & 4.82 & 2503 \\
\hline & & $\mathrm{L}$ & 40 & -50 & -54 & 44 & 3.09 & 286 \\
\hline & & $\mathrm{L}$ & & -46 & -40 & 42 & 5.24 & 2693 \\
\hline & Mid temporal gyrus & $\mathrm{R}$ & & 62 & -30 & 2 & 3.63 & $1115^{*}$ \\
\hline & Mid temporal gyrus & $\mathrm{L}$ & 21 & -60 & -54 & 0 & 3.23 & 56 \\
\hline & Superior temporal gyrus & $\mathrm{L}$ & 42 & -64 & -32 & 18 & 2.73 & 42 \\
\hline & Insula & $\mathrm{L}$ & 13 & -46 & -14 & 10 & 2.67 & 23 \\
\hline \multirow{4}{*}{ Control adult } & Superior frontal gyrus & $\mathrm{L}$ & 6 & -22 & 18 & 58 & 3.11 & 52 \\
\hline & Inferior parietal lobule & $\mathrm{R}$ & 40 & 54 & -44 & 52 & 3.58 & 76 \\
\hline & Precuneus & $\mathrm{R}$ & 7 & 20 & -72 & 48 & 3.20 & 160 \\
\hline & & $\mathrm{L}$ & 7 & -4 & -32 & 44 & 3.04 & 26 \\
\hline \multicolumn{9}{|l|}{ 1-Back-Simple } \\
\hline \multirow[t]{10}{*}{ FAS adults } & Superior frontal gyrus & $\mathrm{R}$ & 10 & 38 & 62 & -2 & 2.89 & $47 \S$ \\
\hline & & $\mathrm{L}$ & 10 & -28 & 66 & 0 & 4.95 & 498 \\
\hline & & $\mathrm{L}$ & 10 & -30 & 56 & 22 & 3.37 & $637 * *$ \\
\hline & Middle frontal gyrus & $\mathrm{L}$ & 10 & -42 & 50 & 10 & 5.40 & $637 * *$ \\
\hline & & $\mathrm{R}$ & 22 & & 42 & 10 & 3.88 & 113 \\
\hline & Inferior frontal gyrus & $\mathrm{R}$ & 10 & 42 & 56 & 2 & 3.53 & $47 \S$ \\
\hline & & $\mathrm{L}$ & & -40 & 30 & 12 & 3.33 & 54 \\
\hline & Cingulate & & & 8 & -6 & 62 & 2.79 & 57 \\
\hline & Inferior parietal & $\mathrm{L}$ & 40 & -44 & -40 & 44 & 6.30 & 23549 \\
\hline & Superior temporal & $\mathrm{R}$ & 22 & 62 & -10 & 2 & 3.83 & 35 \\
\hline \multirow[t]{9}{*}{ Control adult } & Superior frontal gyrus & $\mathrm{R}$ & 6 & 12 & 8 & 62 & 3.89 & $206 \dagger$ \\
\hline & & $\mathrm{L}$ & 6 & -4 & 2 & 64 & 2.72 & $206 \dagger$ \\
\hline & & $\mathrm{L}$ & 10 & -40 & 48 & 22 & 4.69 & 826 \\
\hline & Middle frontal gyrus & $\mathrm{R}$ & 6 & 26 & 0 & 44 & 4.05 & $1911 \ddagger$ \\
\hline & & $\mathrm{L}$ & & -36 & 54 & -18 & 5.00 & 64 \\
\hline & Inferior frontal gyrus & $\mathrm{R}$ & & 54 & 42 & 10 & 3.80 & 528 \\
\hline & Precentral gyrus & $\mathrm{R}$ & 6 & 48 & 4 & 36 & 4.04 & $1911 \ddagger$ \\
\hline & Inferior parietal lobule & $\mathrm{L}$ & 40 & -38 & -52 & 52 & 3.53 & $1911 \div$ \\
\hline & & $\mathrm{L}$ & 40 & -54 & -54 & 42 & 3.28 & 193 \\
\hline
\end{tabular}

$*, * *, \S, \dagger,+$ Local maxima within the same cluster.

prefrontal cortex (DLPFC, bilateral) and anterior cingulate) and in the visual cortex in healthy volunteers. Activations resulting from motor and visual responses were removed from the Blank and One-back tasks by subtraction of the Simple task from each individual data set. The resulting images show clear areas of activation in brain regions involved in WM, at a level of $p<0.01$ for both children and adults (Figs. 2-7).

FMRI results from children. Using the criteria established, only 7 FASD and 13 control children were included in the Simple and One-back subtraction, and only 9 FASD and 14 control children were included in the Simple and Blank subtraction. Representative findings are presented in Fig. 2, which illustrates regions of fMRI activity for the Blank minus Simple task in two FASD subjects and an age- and sex-matched control. Figure 3 illustrates areas of fMRI activity for the One-back task following subtraction of the Simple task in these same subjects. Table 1 outlines the regions of activity observed and Z-score at a level of $p \leq 0.01$, in both FASD and control child subjects corresponding to Figs. 2 and 3.

Increased functional activation was observed in the inferiormiddle frontal and orbital gyrus in children with FASD relative to controls. There was also greater activation in the cingulate cortex at the more inferior brain slices in children with FASD compared with controls. At more superior slices, however, control children demonstrated greater cingulate and frontal activations. Control children also displayed greater parietal activity.

Overall, control children showed an increase in frontal lobe activity with increasing task difficulty, while children with FASD showed the opposite effect. At more superior slice levels, however, both groups of children showed increased parietal and frontal activation with increasing task difficulty.

Functional activity maps of grouped data were generated, which include all FASD subjects ( $n=9$ Blank; $n=7$ One-Back) who met the cut-off, and for control children $(n=8$ Blank; $n=$ 8 One-Back) who were matched to these subjects in age and sex. One sample $t$ test maps of the grouped data $(p<0.01)$ from children are shown in Fig. 6. Table 3 outlines the regions of activity and Z-score, at a level of $p \leq 0.01$, in these two groups.

FMRI results from adults. All 10 FASD adults met the inclusion criteria for the Simple and Blank subtraction, but only 6 could be included in the Simple and One-back subtraction. All 10 adult controls were included in both subtractions. Representative findings are presented in Figs. 4 and 5, which shows activations during the Blank minus Simple and One-back minus Simple tasks 
Table 3. Selected regions of activity for comparison of group activity (one sample t-test) in FASD and control child subjects during blank $(n=9$ FASD; 8 Control $)$ and 1-back $(n=7$ FASD; 8 Control $)$ tasks following subtraction of the $n=0$ task $(p \leq 0.01)$

\begin{tabular}{|c|c|c|c|c|c|c|c|c|}
\hline \multirow[b]{2}{*}{ Task/subject } & \multirow[b]{2}{*}{ Region of interest } & \multirow[b]{2}{*}{ Hemisphere } & \multirow[b]{2}{*}{ Brodmann's area } & \multicolumn{3}{|c|}{ Coordinates } & \multirow[b]{2}{*}{ Z-score } & \multirow[b]{2}{*}{ Cluster size } \\
\hline & & & & $\mathrm{x}$ & $\mathrm{y}$ & $\mathrm{z}$ & & \\
\hline \multicolumn{9}{|l|}{ Blank-Simple } \\
\hline \multicolumn{9}{|l|}{$\begin{array}{l}\text { Control } \\
\text { children }\end{array}$} \\
\hline & Middle frontal gyrus & $\mathrm{R}$ & 6 & 6 & -6 & 56 & 3.90 & 17 \\
\hline & Inferior temporal lobe & $\mathrm{R}$ & 37 & 58 & -54 & -10 & 3.56 & 11 \\
\hline & Occipital lobe, cuneus & $\mathrm{R}$ & 19 & 22 & -88 & 34 & 4.41 & 12 \\
\hline & Precentral gyrus & $\mathrm{R}$ & 6 & 44 & -4 & 54 & 3.96 & 26 \\
\hline \multicolumn{9}{|l|}{ 1-Back-Simple } \\
\hline \multirow[t]{2}{*}{ FAS children } & Frontal lobe & $\mathrm{R}$ & & 22 & -4 & 50 & 5.82 & 27 \\
\hline & & $\mathrm{L}$ & & -28 & 4 & 26 & 7.37 & 19 \\
\hline \multicolumn{9}{|l|}{$\begin{array}{l}\text { Control } \\
\text { children }\end{array}$} \\
\hline & Frontal lobe & $\mathrm{R}$ & & 24 & -22 & 28 & 4.06 & 38 \\
\hline & & $\mathrm{R}$ & & 24 & 0 & 52 & 3.97 & $152 *$ \\
\hline & Inferior frontal gyrus & $\mathrm{L}$ & 9 & -44 & 4 & 30 & 3.02 & 15 \\
\hline & Superior frontal gyrus & $\mathrm{R}$ & 10 & 28 & 58 & 16 & 3.67 & $157 * *$ \\
\hline & & $\mathrm{R}$ & 10 & 34 & 50 & 24 & 2.93 & $157 * *$ \\
\hline & & $\mathrm{L}$ & 9 & -30 & 52 & 30 & 3.50 & 36 \\
\hline & Middle frontal gyrus & $\mathrm{R}$ & & 12 & -10 & 62 & 3.14 & 19 \\
\hline & Precuneus & $\mathrm{R}$ & 7 & 16 & -78 & 46 & 2.85 & 7 \\
\hline & & $\mathrm{L}$ & 7 & -8 & -60 & 48 & 3.35 & 44 \\
\hline & Precentral gyrus & $\mathrm{R}$ & & 40 & -4 & 54 & 3.43 & $152^{*}$ \\
\hline
\end{tabular}

*,**, § Local maxima within the same.

(respectively) for two FASD subjects and an age- and sexmatched control. Table 2 outlines the regions of activity observed and Z-score at a level of $p \leq 0.01$, in both FASD and control adult subjects corresponding to the images shown in Figs. 4 and 5.

Greater orbital and inferior-middle frontal activation was observed in adults with FASD compared with controls during the Blank task. In general, there was a trend toward greater brain activity with increased task difficulty, but while controls showed this pattern in inferior frontal and orbital brain regions, this pattern was not as consistent in the adult FASD group. Greater parietal and frontal activations were observed with increasing task difficulty in both FASD and control adult groups, at more superior slices. Overall, there was less activation in FASD compared with control adults.

The grouped data were generated for all FASD subjects $(n=$ 10 Blank; $n=6$ One-Back) who met the cut-off, and for appropriate age- and sex-matched controls $(n=9$ Blank; $n=$ 6 One-Back). Figure 7 illustrates grouped data resulting from a one sample $t$ test $(p<0.01)$ of the two adult groups. Table 4 outlines the regions of activity observed and Z-score at a level of $p \leq 0.01$, in these two groups.

Anatomical MRI. There were no notable differences observed in the anatomical scans between FASD and control subjects (data not shown).

\section{DISCUSSION}

While FASD is characterized by diverse behavioral and physical effects, common deficits include problems with impulsivity, attention, executive function and WM. Past research has suggested a strong role for prefrontal cortex, posterior parietal cortex and Broca's area in WM function (14-19). As such, we expected that difficulties in WM would be evident in individuals with FASD, and be associated with damage or dysfunction in these brain regions.

Both children and adults with FASD showed increased functional activity in the inferior and middle frontal cortex compared with age- and sex-matched controls, particularly during the Blank task. Children with FASD showed a decrease in inferior frontal cortex functional activity with increasing task difficulty, while control children and adults showed the opposite pattern (see Figs. 2-7). All subjects demonstrated increased frontal cortex fMRI activity at superior slice levels with increasing task difficulty. Moreover, the adult FASD group also showed greater activation in the superior frontal cortex, relative to their controls. Together, these group differences in activation patterns seen during this test of spatial working memory suggest improper functioning of prefrontal areas in individuals with FASD. In similar 2-back task fMRI 
Table 4. Selected regions of activity for comparison of group activity (one sample $t$-test) in FASD and control adult subjects during blank $(n=10$ FASD; 9 Control $)$ and 1-back $(n=6$ FASD; 6 Control $)$ tasks following subtraction of the $n=0$ task $(p \leq 0.01)$

\begin{tabular}{|c|c|c|c|c|c|c|c|c|}
\hline \multirow[b]{2}{*}{ Task/subject } & \multirow[b]{2}{*}{ Region of Interest } & \multirow[b]{2}{*}{ Hemisphere } & \multirow[b]{2}{*}{ Brodmann's area } & \multicolumn{3}{|c|}{ Coordinates } & \multirow[b]{2}{*}{ Z-score } & \multirow[b]{2}{*}{ Cluster size } \\
\hline & & & & $\mathrm{x}$ & $\mathrm{y}$ & $\mathrm{z}$ & & \\
\hline \multicolumn{9}{|l|}{ Blank-Simple } \\
\hline \multirow{7}{*}{ FAS adults } & Middle frontal gyrus & $\mathrm{R}$ & 46 & 46 & 50 & 14 & 4.51 & 9 \\
\hline & & $\mathrm{L}$ & & -18 & 6 & 58 & 6.52 & 25 \\
\hline & Precentral gyrus & $\mathrm{L}$ & 6 & -46 & -4 & 54 & 4.05 & 63 \\
\hline & & $\mathrm{L}$ & 6 & -48 & -6 & 34 & 3.94 & 26 \\
\hline & Parietal lobe, precuneus & $\mathrm{R}$ & 7 & 22 & -70 & 40 & 3.03 & 7 \\
\hline & & $\mathrm{L}$ & 19 & -14 & -82 & 40 & 3.58 & 25 \\
\hline & Occipital lobe, cuneus & $\mathrm{R}$ & 19 & 30 & -84 & 22 & 4.46 & 55 \\
\hline \multicolumn{9}{|l|}{ Control adults } \\
\hline & Superior frontal gyrus & $\mathrm{L}$ & 10 & -34 & 56 & -2 & 3.54 & 10 \\
\hline & Inferior frontal gyrus & $\mathrm{L}$ & & -44 & 30 & -8 & 4.09 & 16 \\
\hline & Inferior parietal lobe & $\mathrm{L}$ & & -44 & -44 & 22 & 3.08 & 3 \\
\hline & Superior temporal gyrus & $\mathrm{L}$ & 22 & -62 & -52 & 14 & 4.55 & 18 \\
\hline \multicolumn{9}{|l|}{ 1-Back-Simple } \\
\hline \multirow[t]{9}{*}{ FAS adults } & Frontal lobe & $\mathrm{L}$ & & -36 & 18 & 22 & 11.98 & 35 \\
\hline & & $\mathrm{L}$ & & -16 & 8 & 56 & 6.17 & 51 \\
\hline & Precentral gyrus & $\mathrm{R}$ & 6 & -52 & 2 & 44 & 5.23 & 14 \\
\hline & & $\mathrm{L}$ & & -42 & 0 & 36 & 4.13 & 35 \\
\hline & Superior frontal gyrus & $\mathrm{L}$ & 10 & -18 & 66 & 10 & 4.86 & 2 \\
\hline & & $\mathrm{L}$ & & -16 & 62 & -2 & 3.74 & 4 \\
\hline & Middle frontal gyrus & $\mathrm{L}$ & 6 & -24 & -12 & 58 & 3.70 & 3 \\
\hline & & $\mathrm{L}$ & & -30 & 50 & 34 & 13.95 & 35 \\
\hline & Parietal lobe, precuneus & $\mathrm{R}$ & 7 & 24 & -76 & 46 & 5.32 & 90 \\
\hline \multicolumn{9}{|l|}{ Control adults } \\
\hline & Inferior frontal gyrus & $\mathrm{L}$ & 46 & -52 & 44 & 4 & 5.72 & 255 \\
\hline & Superior frontal gyrus & $\mathrm{R}$ & 6 & 4 & 6 & 60 & 4.28 & 63 \\
\hline & & $\mathrm{L}$ & 6 & -8 & 8 & 60 & 4.87 & $56 * *$ \\
\hline & & $\mathrm{L}$ & 6 & -10 & 12 & 52 & 4.47 & $56^{* *}$ \\
\hline & Middle frontal gyrus & $\mathrm{R}$ & 9 & -28 & 34 & 34 & 20.73 & 180 \\
\hline & & $\mathrm{R}$ & 8 & -40 & -46 & 10 & 9.70 & 175 \\
\hline & & $\mathrm{R}$ & 9 & -38 & 22 & 30 & 7.50 & 22 \\
\hline & & $\mathrm{R}$ & 6 & 56 & 4 & 40 & 5.89 & $216^{*}$ \\
\hline & Precuneus & $\mathrm{R}$ & 19 & 24 & -78 & 34 & 3.93 & 36 \\
\hline & Precentral gyrus & $\mathrm{R}$ & 9 & 38 & 6 & 34 & 6.70 & $216^{*}$ \\
\hline & & $\mathrm{L}$ & 6 & -40 & 0 & 36 & 4.27 & 9 \\
\hline & Superior temporal gyrus & $\mathrm{L}$ & 22 & 62 & -56 & 18 & 5.90 & 9 \\
\hline & Insula & $\mathrm{R}$ & & 32 & -16 & 18 & 8.68 & 145 \\
\hline
\end{tabular}

*, ** Local maxima within the same cluster.

studies, control subjects demonstrated activation in the left DLPFC while FASD subjects showed very little activity in this brain region and significantly worse task performance (20).

The differences between FASD and control subjects in frontal lobe activation described above probably contributed to observed group differences in spatial working memory and strategic memory performance observed in the $n$-back and SOP tasks. It seems unlikely that failure to maintain attention to the $n$-back tasks contributed to differences in activation patterns, since only mean latency of correct responses was found to show significant difference between FASD and control groups in the CPT. No significant differences were observed between FASD and control subjects in percent correct responses, probability of a hit or probability of a false alarm. The fact that group differences in activation of the frontal lobe were very similar in children and adults also corresponds well with behavioral testing results, in which few significant age-related differences were observed.

The parietal cortex, involved in discrimination, response selection and memory, showed greater activation during the
Blank task in control compared with FASD participants. All four groups showed increased parietal fMRI activity at more superior slice levels with increasing task difficulty. This is in agreement with previous studies showing that neuronal activation of prefrontal and parietal cortices increases with greater levels of WM load $(14,15,17,18)$. Activation in parietal areas has been linked to accuracy and effort required to meet the memory demands of a spatial task (21).

Other fMRI studies involving similar WM tasks in children and adults have yielded results similar to those reported here. In particular, regions of activity include the right superior frontal gyrus, right DLPFC, right superior parietal cortex and bilateral inferior parietal cortex activations (22). Positron emission tomography (PET) studies have shown predominantly right hemisphere activation in the frontal cortex $(21,23)$, posterior parietal cortex (21) and anterior cingulate (21) of children and young adults, but bilateral activation in older adults (23). While spatial (n-back) WM tasks activate bilaterally, there are key regions (DLPFC and posterior parietal cortex) that have shown activation predominantly in the right- 
hemisphere (19). The current study is in agreement with these findings as activations in adult subjects were mainly either right-hemisphere or bilateral in both frontal and parietal regions for both FASD and control groups. Children with FASD also demonstrated mainly bilateral or right hemisphere activations in the frontal and parietal brain regions, but results from control children were more varied.

All subjects also consistently showed activation in the cingulate region, which is involved in affective behaviors, nociception, and executive functions (24). Its activity, which is modulated by task demands and response selection, has been shown to increase during WM tasks in both children and adults $(16,21,25)$. It has been suggested, however, that these increases (and those seen in extrastriate regions) are more closely linked to the attention demands of WM tasks, than to the memory demands themselves (which have been associated with DLPFC and parietal activations) (21). Given this, the consistent anterior cingulate activity observed in this study may reflect the fact that participants in all four groups were paying attention to the task, a conclusion strengthened by the fact that FASD and control groups performed similarly on the CPT. This is important as attention is commonly affected in FASD, and is therefore a major concern when performing fMRI studies and interpreting the results (26-29). Other researchers have suggested that problems with visual perception (26) and impulsivity (28) may have contributed to poor performance in previous CPT studies.

In standard psychological tests, children with FAS have been shown to identify fewer categories correctly and to make significantly more perseverative errors on the WCST than controls $(9,27)$. While we observed some trends toward better performance on the WCST in adult controls relative to FASD adults (cf. 8), these effects were not strong, and were absent in children. These findings are consistent with the conclusion from Kodituwakku et al. that individuals with FAS can display problems with WM without showing associated problems on tasks requiring rule learning and response inhibition (9).

The fMRI results in conjunction with the results of the psychological tests suggest impairment in spatial WM in children and adults with FASD. At least two different brain areas show distinctly different activation patterns in FASD participants, relative to controls, suggesting the potential for fMRI as an adjunctive diagnostic tool. Studies involving larger numbers of participants may help to identify sub-groups of affected individuals. The use of fMRI may prove to be of particular importance in cases where diagnosis is difficult to ascertain (e.g., no facial dismorphology and/or unconfirmed history of maternal alcohol consumption) or complicated by the presence of comorbid conditions (i.e., ADHD).

Acknowledgments. We gratefully acknowledge the assistance of Mary Cox-Miller, Coordinator of the Clinic for Alcohol and Drug Exposed Children, Child and Family Services Departments of the Province of Manitoba, Mr. Graham Wylie at the Association for Active Living Manitoba and Brenda Bennett, Project Coordinator for the Fetal Alcohol Syndrome Community Mobilization Project for assistance with recruitment for this study. We would also like to thank Dr. Patrick
Stroman for use of Matlab programs for conversion of GE imaging data to the appropriate analysis formats.

\section{REFERENCES}

1. Clarren S 1986 Neuropathology in fetal alcohol syndrome. In: West JR (ed) Alcohol and Brain Development. Oxford University Press, New York, pp 158-166.

2. Archibald SL, Fennema-Notestine C, Gamst A, Riley EP, Mattson SN, Jernigan TL 2001 Brain dysmorphology in individuals with severe prenatal alcohol exposure. Dev Med Child Neurol 43:148-154

3. Sowell ER, Thompson PM, Mattson SN, Tessner KD, Jernigan TL, Riley EP, Toga AW 2001 Voxel-based morphometric analyses of the brain in children and adolescents prenatally exposed to alcohol. Neuroreport 12:515-523

4. Bookstein FL, Sampson PD, Streissguth AP, Connor PD 2001 Geometric morphometrics of corpus callosum and subcortical structures in the fetal-alcohol-affected brain. Teratology $64: 4-32$

5. Mattson SN, Riley EP, Gramling L, Delis DC, Jones KL 1997 Heavy prenatal alcohol exposure with or without physical features of fetal alcohol syndrome leads to IQ deficits. J Pediatr 131:718-721

6. Mattson SN, Schoenfeld AM, Riley EP 2001 Teratogenic effects of alcohol on brain and behavior. Alcohol Res Health 25:185-191

7. Mattson SN, Riley EP 1999 Implicit and explicit memory functioning in children with heavy prenatal alcohol exposure. J Int Neuropsychol Soc 5:462-471

8. Connor PD, Sampson PD, Bookstein FL, Barr HM, Streissguth AP 2000 Direct and indirect effects of prenatal alcohol damage on executive function. Dev Neuropsychol 18:331-354

9. Kodituwakku PW, Handmaker NS, Cutler SK, Weathersby EK, Handmaker SD 1995 Specific impairments in self-regulation in children exposed to alcohol prenatally. Alcohol Clin Exp Res 19:1558-1564

10. Chudley AE, Conroy J, Cook JL, Loock C, Rosales T, LeBlanc N ; Public Health Agency of Canada's National Advisory Committee on Fetal Alcohol Spectrum Disorder 2005 Fetal alcohol spectrum disorder: Canadian guidelines for diagnosis. CMAJ 172:S1-S21.

11. Friston KJ, Jezzard P, Turner R 1994 Analysis of functional MRI time-series. Hum Brain Mapp 1:153-171

12. Wilke M, Schmithorst VJ, Holland SK 2002 Construction of Gender Specific Pediatric Templates for Spatial Normalization with SPM99. Proc Intl Soc Mag Res Med 10: May 18-24, Honolulu, HI

13. Evans AC, Collins DL, Mills SR, Brown ED, Kelly RL 1993 3D statistical neuroanatomical models from 305 MRI volumes. IEEE Conference Record, Nuclear Science Symposium and Medical Imaging Conference 3:1813-1817.

14. Casey BJ, Cohen JD, O'Craven K, Davidson RJ, Irwin W, Nelson CA, Noll DC, Hu X, Lowe MJ, Rosen BR, Truwitt CL, Turski PA 1998 Reproducibility of fMRI results across four institutions using a spatial working memory task. Neuroimage 8:249-861

15. Braver TS, Cohen JD, Nystrom LE, Jonides J, Smith EE, Noll DC 1997 A parametric study of prefrontal cortex involvement in human working memory. Neuroimage 5:49-62

16. Barch DM, Braver TS, Nystrom LE, Forman SD, Noll DC, Cohen JD 1997 Dissociating working memory from task difficulty in human prefrontal cortex. Neuropsychologia 35:1373-1380

17. Cohen JD, Perlstein WM, Braver TS, Nystrom LE, Noll DC, Jonides J, Smith EE 1997 Temporal dynamics of brain activation during a working memory task. Nature 386:604-608

18. Jonides J, Schumacher EH, Smith EE, Koeppe RA, Awh E, Reuter-Lorenz PA, Marshuetz C, Willis CR 1998 The role of parietal cortex in verbal working memory. J Neurosci 18:5026-5034

19. Smith EE, Jonides J, Koeppe RA 1996 Dissociating verbal and spatial working memory using PET. Cereb Cortex 6:11-20

20. Connor P, Mahurin RA 2001 Preliminary Study of Working Memory in Fetal Alcohol Damage Using fMRI. J Int Neuropsychol Soc 7:206

21. Nelson CA, Monk CS, Lin J, Carver LJ, Thomas KM, Truwit CL 2000 Functional neuroanatomy of spatial working memory in children. Dev Psychol 36:109-116

22. Thomas KM, King SW, Franzen PL, Welsh TF, Berkowitz AL, Noll DC, Birmaher V, Casey BJ 1999 A developmental functional MRI study of spatial working memory. Neuroimage 10:327-338

23. Reuter-Lorenz PA, Jonides J, Smith EE, Hartley A, Miller A, Marshuetz C, Koeppe RA 2000 Age differences in the frontal lateralization of verbal and spatial working memory revealed by PET. J Cogn Neurosci 12:174-187

24. Devinsky O, Morrell MJ, Vogt BA 1995 Contributions of anterior cingulate cortex to behaviour. Brain 118:279-306

25. Carter CS, Braver TS, Barch DM, Botvinick MM, Noll D, Cohen JD 1998 Anterior cingulate cortex, error detection, and the online monitoring of performance. Science 280:747-749

26. Coles CD, Platzman KA, Lynch ME, Freides D 2002 Auditory and visual sustained attention in adolescents prenatally exposed to alcohol. Alcohol Clin Exp Res 26:263-271

27. Coles CD, Platzman KA, Raskind-Hood CL, Brown RT, Falek A, Smith IE 1997 A comparison of children affected by prenatal alcohol exposure and attention deficit, hyperactivity disorder. Alcohol Clin Exp Res 21:150-161

28. Streissguth AP, Barr HM, Sampson PD, Parrish-Johnson JC, Kirchner GL, Martin DC 1986 Attention, distraction and reaction time at age 7 years and prenatal alcohol exposure. Neurobehav Toxicol Teratol 8:717-725

29. Streissguth AP, Bookstein FL, Sampson PD, Barr HM 1995 Attention: prenatal alcohol and continuities of vigilance and attentional problems from 4 through 14 years. Develop Psychopath 7:419-446 